\title{
Personal view: on the receiving end
}

John Collee, in his column in The Observer, said that a febrile illness should be compulsory for every doctor, as it reminds one of what being a patient is like. Having been ill recently myself, I can only endorse this view. I rather overdid it in that I acquired a severe head injury which resulted in admission to hospital for six months. As a psychiatrist with a head injury I found myself in a near unique position in that I not only had the experience of being a patient but can now understand some of the psychological processes of recovering from a head injury. Although neuropsychiatry was a field I was interested in. I would not have chosen this method of investigating it!

A belief among health professionals is that head-injured patients are irritable. Given that recovery from a head injury is nothing less than coming back from the dead, melodramatic but true, the 'irritability' is not that much of a surprise. The task faced is enormous. The experience of illness makes us generally ratty because our bodies are occupied with getting better, and this takes a lot of energy. Some of the most complicated things to cope with are the reactions of others. These vary from people who do not know to those who do and blame everything on the head injury, so that it absolves them of responsibility for their actions. Personally, I am quite relieved that I have to walk with a stick as it is a kind of badge which says that everything is not $100 \%$ normal, and the effect is to elicit kindness. But there is still the irritating tendency of others to attribute everything to the injury.

\section{The insider's view of some cerebral functions}

My experience of getting better was essentially of regaining cerebral abilities I had lost. This may seem obvious with hindsight as one of the aspects of recovery from an illness is the recovery of lost functions. Most will remember the story of Phineas Gage who gave himself a frontal lobotomy after which his personality completely changed. Previously industrious and considerate, he became lazy, rude, given to excesses such as gluttony and was rash financially. $\mathrm{He}$ is the classic example of the 'frontal lobe syndrome'. Although I hope I was not as bad as Phineas Gage I can vouch for the frontal lobes being where adult functioning resides. I remember feeling perturbed that those around me did not know what I was thinking or what my preferred action in any situation would be. (The disorientation which accompanies head injury as well as the memory deficits contributed to the irritability.) Getting better was becoming an adult again.

Being a doctor on the receiving end leads to behaviour which is recognisable as resulting from the extremity of the situation. Bettelheim (1991) wrote about his imprisonment in a concentration camp; to survive he fell back on his profession as psychoanalyst. While I would never presume to compare my experience with the horrors of a concentration camp, it was certainly an extreme situation being a health professional on the receiving end.

I found myself falling back into a familiar role. When I was first able to speak, I would launch into technical terms, such as asking for the spigot of my naso-gastric tube. It is a relief that I cannot remember the whole experience including, for example, being doubly incontinent, and unable to walk to the ward toilet or unable to wait for a bedpan. For this reason, I believe that the amnesia associated with head injury can be protective.

I also noticed how often I was kept waiting for people who would be called away for just a minute'. One of my favourite members of staff was the physiotherapist who, if she said she was going to be back in ten minutes, would be accurate to the second. I found the experience of waiting around unpleasant which is why I appreciated the physiotherapist's accuracy, and indeed as a patient you have to wait for everything. In my case, I had previously been very healthy so the change was very noticeable. (Of course, the experience of 1ll-health must be unpleasant no matter how robust one's previous health.) With the world shrunk down to the hospital ward and its environs, everything there becomes more significant because there does not seem to be anything else. Any actions by the staff are important: a difficult aspect of health work. but one which matters.

I end with a plea for a little more patience and understanding and a request not to retreat into stereotypes when considering a patient's situation, but to listen.

\section{Reference}

Betтelhem, B. (1991) The Informed Heart. London: Penguin.

Name and address supplied 